\title{
Anti-Aging and Enhanced Physique Activities Research of Astragalus Mongolicus Water Extract in Mice
}

\author{
Li-Jun $\mathrm{Yu}^{1}$, Ao Wuliji ${ }^{2}$, Shu-Yin Bao ${ }^{1}$, Guo-Hua Gong ${ }^{1,3}{ }^{\text {* }}$ \\ ${ }^{1}$ Medicinal Chemistry and Pharmacology Institute, Inner Mongolia University for the Nationalities, Tongliao 028000, Inner Mongolia, P.R. China \\ ${ }^{2}$ College of Traditional Mongolian Medicine, Inner Mongolia University for Nationalities, Tongliao 028000, Inner Mongolia, P.R. China \\ ${ }^{3}$ Affiliated Hospital of Inner Mongolia University for Nationalities, Tongliao 028007, Inner Mongolia, P.R. China
}

*Corresponding author: Guo-Hua Gong, No. 1742 Holin he Street, Tongliao 028000, Inner Mongolia, P.R. China, Tel: +864-332-436-020; Email:gongguohua0211@163.com

Received date: February 16, 2015, Accepted date: May 08, 2015, Published date: May 13, 2015

Copyrights: $\odot 2015$ Gong GH, et al. This is an open-access article distributed under the terms of the Creative Commons Attribution License, which permits unrestricted use, distribution, and reproduction in any medium, provided the original author and source are credited

\begin{abstract}
The present study aimed to investigate the biological activities of Astragalus mongolicus (AM) water extract in mice. Mice intraperitoneally received D-gal $300 \mathrm{mg} / \mathrm{kg}$, and orally administered with AM water extract $(6,12$ or 24 $\mathrm{g} / \mathrm{kg}$ ) once daily for 56 days, the results of ethological examination exhibited that D-gal can weaken spatial memory function of mice in the Morris water maze test; further analysis demonstrated that the capacity of oxidative stress mediated by oxidase was enhanced in D-gal-injected mice. The decreased activities of SOD and GSH-Px and the increased activity of CAT could be found in hippocampus induced by D-gal. Based on the results above, we inferred and explored enhanced memory and physique abilities of AM water extract using three mice models (water maze test, swim test and beheaded breathing test), the results exhibited that AM water extract could prolong the swimming time, the breathing time and survival time. This work indicated that AM water extract was very helpful to organism, and the protective effect may relate to oxidative stress.
\end{abstract}

Keywords: Astragalus mongolicus water extract; D-gal; Aging; Physique activity

\section{Introduction}

Astragalus membranaceus is also named Huang Qi (HQ), and it is a typical traditional chinese medicine (TCM) plant, and has presented for many years on the Western market (in Europe and USA) as food supplement. HQ has also been used for thousands of years in China and East Asia for kidney diseases, and in modern Chinese medicine, it seems to have renal protective effect in diabetic nephropathy [1]. The extract of the HQ root is usually used in Western phytotherapy as galenic preparations, containing dried extract standardized in polysaccharides, the substances that are mostly considered to be responsible for the presumed immunostimulant properties [2]: it is in particular used for recurrent respiratory diseases or as therapeutic complement in cancer treatment [3]. HQ injection is a preparation of an extract of Radix Astragali: the major components are astragalosides [4], other pharmacological ingredients include polysaccharides, flavones and amino acids. Modern pharmacological research has shown that HQ injection can enhance myocardial contractility, improve circulation, protect myocardial cells and regulate immunity[5,6].

$\mathrm{D}$-galactose (D-gal) is a dialdehyde sugar that can be metabolized at body's normal concentration as the normal nutrient. However, the oxidase or dehydrogenase galacturonic can be generated at high levels of D-gal, and may be further metabolized to xylulose with generating superoxide anion and oxygen-derived free radicals, excess oxygen free radicals can cause oxidative stress. And advanced glycation end products (AGEs) could be formed by D-galactose readily reacting with the free amines of amino acids in proteins and peptides. Evidence shows that AGEs can significantly cause the accumulation of reactive oxygen species (ROS), especially superoxide radicals and hydrogen peroxide.

Astragalus mongholicus (AM) derives from the dry root of Astragalus membranaceus Bge. var. mongolicus (Bge.) Hsiao. Some reports exhibited that AM could protect animals from kinds of injury of brain [7-10]. So in this work, we investigated the protective effects of AM on D-gal induced memory impairment in vivo and physique activities of AM using three mice models (water maze test, swim test and beheaded breathing test).

\section{Materials and Methods}

\section{Animal experiments}

The experiments were carried out on adult KunMing male mice (18-22 g) purchased from Animal Center of Jilin University and adapt to conditions for 7 days. Mice were housed in a quiet, temperatureand humidity-controlled room $\left(22 \pm 2^{\circ} \mathrm{C}\right.$ and $60 \pm 5 \%$, respectively) with a 12-h light/dark cycle with food and water continuously available. All experiments were performed at the same time of day during the light period. All procedures in the present study were performed in accordance with the Guide for the Care and Use of Laboratory Animals as adapted by the National Institutes of Health (Washington, DC, USA, 1996). Local ethical committee approval was also obtained. All efforts were made to minimize animal suffering and to reduce the number of animals used.

\section{D-gal induced memory impairment}

60 animals were randomly divided into five groups with twelve each group. Group I was as control group: mice were treated with distilled water $(5 \mathrm{ml} / \mathrm{kg})$ orally. Group II was as model group: mice were 
Page 2 of 4

treated with distilled water $(5 \mathrm{ml} / \mathrm{kg})$ orally and D-galactose (300 $\mathrm{mg} / \mathrm{kg}$ ) by ip. Group III was as low dose of AM group: mice were treated with AM water extract $(6 \mathrm{~g} / \mathrm{kg})$ orally and D-galactose $(300$ $\mathrm{mg} / \mathrm{kg}$ ) by ip. Group IV was as middle dose AM group: mice were treated with AM water extract $(12 \mathrm{~g} / \mathrm{kg})$ orally and D-galactose $(300$ $\mathrm{mg} / \mathrm{kg}$ ) by ip. Group V: mice were treated with AM water extract (24 $\mathrm{g} / \mathrm{kg}$ ) orally and D-galactose $(300 \mathrm{mg} / \mathrm{kg})$ by ip. All the mice were treated twice daily for 56 days and given normal diet. On the last day of experiment, the mice were deprived of food overnight, behavior evaluation was performed the next day. At last, blood from eyes was collected in polystyrene tubes without the anticoagulant. Serum was immediately separated by centrifugation at $3,000 \mathrm{rpm}$ at room temperature for $10 \mathrm{~min}$ and assayed for activities of GSH-PX, SOD, CAT.

\section{Water maze test}

The water maze test is a widely accepted method for memory test, thus we performed this test as the method to determine memory impairment. Maze testing was performed by the TaiMeng program and equipment (ChengDu, China). A circular plastic pool (height: 35 $\mathrm{cm}$, diameter: $110 \mathrm{~cm}$ ) was filled with water (with dark ink) which was kept at 22-25. An escape platform (height: $14.5 \mathrm{~cm}$, diameter: $4.5 \mathrm{~cm}$ ) was submerged $0.5-1 \mathrm{~cm}$ below the surface of the water. Mice were trained twice per day for 5 days. Each trial lasted for $60 \mathrm{~s}$ or ended as soon as the mice reached the submerged platform and remained on the platform for $10 \mathrm{~s}$. Mice were allowed to swim until they sought the escape platform. Escape latency, escape distance, swimming speed and swimming pattern of each mouse was monitored by a camera above the center of the pool connected to a SMART-LD program. A quiet environment, consistent lighting, constant water temperature and fixed spatial frame were maintained throughout the period of the experiment.

\section{Antioxidant enzyme activities of serum}

Antioxidant enzyme activities were assayed with superoxide dismutase (SOD) activity assay kit (Nanjing, Jiancheng), Glutathione peroxidase (GSH-PX) assay kit (Nanjing, Jiancheng) and Catalase (CAT) assay kit (Nanjing, Jiancheng). The assay was in accordance with the manufacturer's instructions.

\section{Physique activities experiment}

80 male mice were randomly divided into four groups with 20 mice of each group. Group I: normal control (NC), mice were treated with distilled water $(5 \mathrm{ml} / \mathrm{kg}$ ). Group II: mice were treated with $6 \mathrm{~g} / \mathrm{kg} \mathrm{AM}$ water extract. Group III: mice were treated with $12 \mathrm{~g} / \mathrm{kg}$ AM water extract. Group IV: mice were treated with $24 \mathrm{~g} / \mathrm{kg}$ AM water extract. All the mice were treated twice daily for 7 days and given normal diet. Behavior evaluation was at the end of administration.

\section{Swim test}

10 mice were selected randomly from the four groups respectively for swimming experiments. After $1 \mathrm{~h}$ of the last administration with AM water extract, animals were put into the swimming tank (the depth of the water was not less than $30 \mathrm{~cm}$, the water temperature was controlled at $25 \pm 0.5$ and $5 \%$ body weight load was added to root of mice tails), time period was recorded from putting animals into water to death (mice stayed on the bottom for 5 seconds).

\section{Beheaded breathing test}

10 mice were selected randomly from the four groups respectively for beheaded breathing test. After $1.5 \mathrm{~h}$ of the last administration with AM water extract, mice were beheaded, time period was recorded from beheaded to death (mice stay mouth close for 5 seconds).

\section{Statistical analysis}

Data were shown as mean with standard deviation. Values of $\mathrm{p}<0.05$ were considered as significant difference. Behavioral data were analyzed with one-way analysis of variance (ANOVA).

\section{Results}

To examine the effect of AM on memory impairment induced by D-gal using the Morris water maze, the mice were continuously administered with AM water extract at a dose of 6,12 and $24 \mathrm{~g} / \mathrm{kg}$ by oral and D-gal $300 \mathrm{mg} / \mathrm{kg}$ by ip for 8 weeks respectively, and then the animals were trained 10 times ( 2 twice/ 5 days) by the water maze test. Mice in Group II slowly arrived at the location of the platform compared to group I, and impairment by D-gal in all the mice of three groups treated with AM water extract (group III, IV and V) were improved on ability of escape latency (Figure 1). The mice exhibited shorter and shorter escape latency by the end of the training trial.

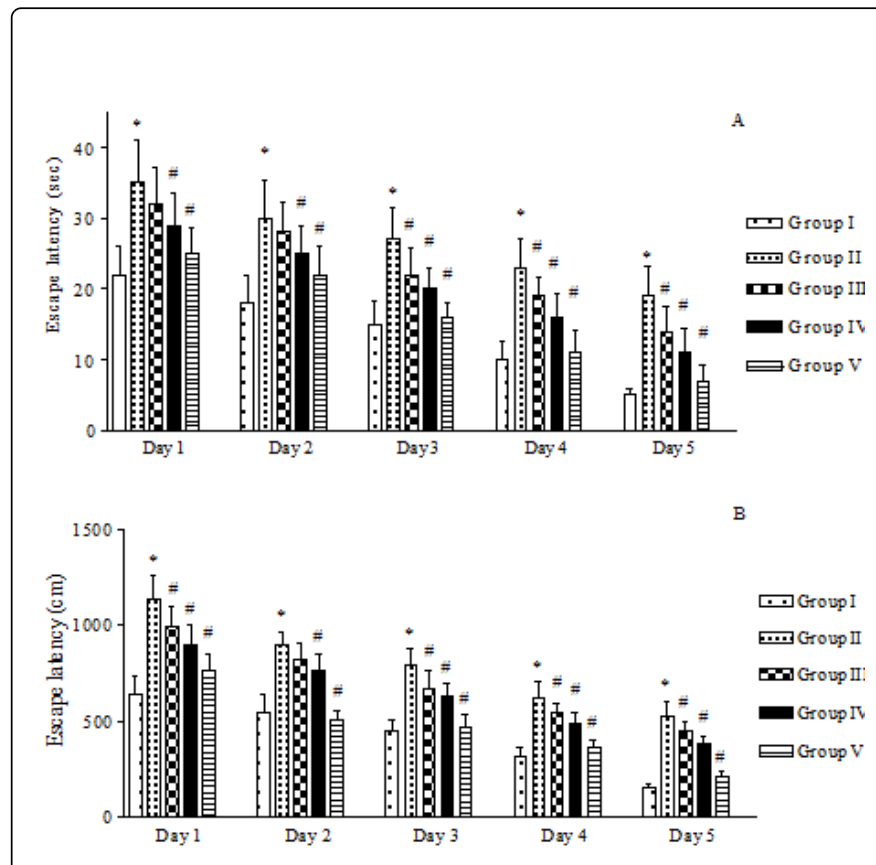

Figure 1: Effect of AM on memory dysfunction in KunMing mice

Training trials were performed twice per day for 5 days. (A) Swimming time and (B) swimming distance to arrive at the platform. Values are presented as means $\pm \mathrm{SD}$ from 12 mice, ${ }^{\star} \mathrm{p}<0.05$, different from group I, and $\# \mathrm{p}<0.05$, different from group II.

The levels of T-SOD, GSH-Px and CAT in the serum of mice were measured. SOD level of serum in AM treated mice was significantly decreased compared to that in the $\mathrm{CN}$ group, and the concentration of SOD was significantly increased with the increasing dose of AM Figure 
2A. GSH-Px level of serum in AM treated mice was significantly decreased compared to that in the $\mathrm{CN}$ group, and the concentration of SOD was significantly increased with the increasing dose of AM Figure 2B. CAT level of serum in AM-treated mice was significantly increased compared to that in the $\mathrm{CN}$ group, and with the increasing dose of $\mathrm{AM}$, the concentration of SOD was significantly decreased Figure 2C.
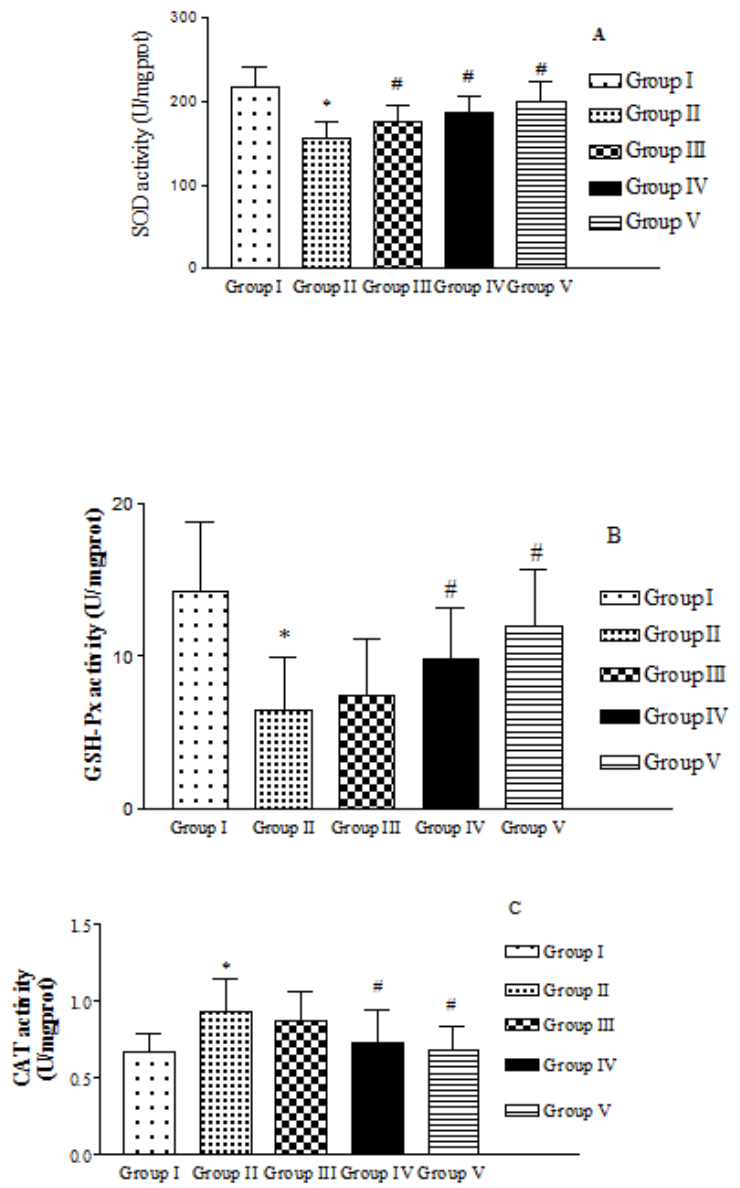

Figure 2: Antioxidant effect of AM in D-gal induced aging model

Based on the results above, we inferred and explored the enhanced physique activities of AM water extract using two mice models (swim test and beheaded breathing test). The results of swimming test and beheadent breathing test were shown in the Figure 3, as is shown in Figure $3 \mathrm{~A}$, the swimming time prolonged with the increasing dose of $\mathrm{AM}$ water extract, and the breathing time prolonged with the increasing dose of AM water extract too (Figure 3B).
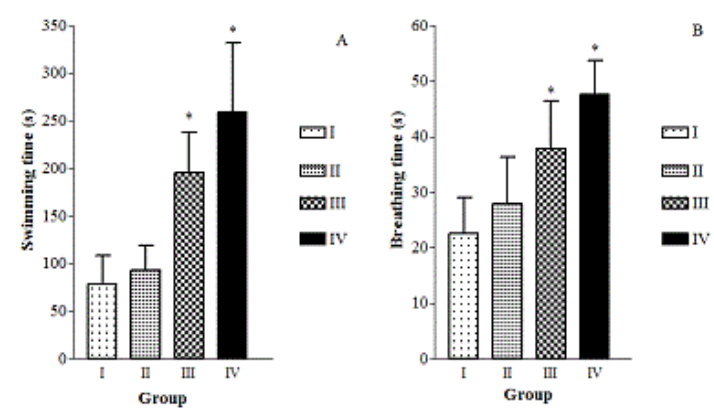

Figure 3: The swimming time and the breathing time $\left({ }^{*} \mathrm{p}<0.05\right.$, compared with group I)

\section{Discussion}

Alzheimer's disease (AD) is the most common cause of dementia, accounting for $50 \%$ to $75 \%$ of all cases [11]. Oxidative stress is believed to be a primary factor in the normal process of aging [12]. It is well known that mitochondrial dysfunction and activation of caspases caused by oxidative stress and apoptotic cell death could be increased by exogenous $\mathrm{H}_{2} \mathrm{O}_{2}$. Furthermore, superoxide dismutase (SOD), catalase (CAT), and glutathione peroxidase (GSH-Px) act by scavenging the superoxide anion and $\mathrm{H}_{2} \mathrm{O}_{2}$ to prevent reactiveoxygen-species- (ROS-) induced damage [13]. D-galactose (D-gal) induced oxidative stress test was often used to selected medicine with anti-oxidative stress and anti-aging activity [14-17]. The results exhibited that administration of D-gal $300 \mathrm{~g} / \mathrm{kg}$ daily for 8 weeks prior to training induced a significant increase in memory injury, oxidative stress was also induced by D-gal. Our study demonstrated that AM water extract (more than $12 \mathrm{~g} / \mathrm{kg}$ p.o.) could reverse all the alterations induced by D-gal. In other word that AM water extract could protect the memory from impairment induced by $\mathrm{D}$-gal in mice, and the more AM water extract was intake, the more protective effects on oxidative stress induced by D-gal in mice would be produced. Thus, the study indicated that AM water extract may have a protective effect against $\mathrm{AD}$ via modulating oxidative stress. These results suggest that further study is necessary to evaluate the effect of AM on damage of memory and to determine the molecular mechanisms. D-gal administration sequentially affected multiple-pathways, including protein transport and signal transduction, which could play key roles in maintaining the stability of synaptic structures [18]. The swimming and beheaded breathing tests results exhibited that AM water extract could prolong the swimming time, the breathing time and survival time. All the work results indicated that AM water extract was very helpful to organism, and the protective effect may relate to oxidative stress. In conclusion, D-gal increased ROS production induced by oxidative stress and lipid peroxidation and also maintained endogenous antioxidant enzymatic activities, stabilized mitochondrial function. These results should encourage further studies to explore the potential mechanism of AM effects on aging in neurologic diseases. It is possible that AM acts through several mechanisms, mediating a potential role in memory damage and improved physique activities in mice. This work indicated that AM water extract was very helpful to organism, and the protective effect may relate to oxidative stress. 
Citation: Yu LJ, Wuliji A, Gong GH (2015) Anti-Aging and Enhanced Physique Activities Research of Astragalus Mongolicus Water Extract in Mice. Clin Exp Pharmacol 5: 175. doi:10.4172/2161-1459.1000175

Page 4 of 4

\section{Acknowledgement}

This work was supported by National Science-tech Support Plan: Quality standard and pharmacodynamics research of characteristic Mongolian medicine and Commonly used Mongolian compound (No. 2011CB512011).

\section{References}

1. Li M, Wang W, Xue J, Gu Y, Lin S (2011) Meta-analysis of the clinical value of Astragalus membranaceus in diabetic nephropathy. J Ethnopharmacol 133: 412-419.

2. Denzler KL, Waters R, Jacobs BL, Rochon Y, Langland JO (2010) Regulation of inflammatory gene expression in PBMCs by immunostimulatory botanicals. PLoS One 5: e12561.

3. Cho WC, Leung KN (2007) In vitro and in vivo anti-tumor effects of Astragalus membranaceus. Cancer Lett 252: 43-54.

4. Tohda C, Tamura T, Matsuyama S, Komatsu K (2006) Promotion of axonal maturation and prevention of memory loss in mice by extracts of Astragalus mongholicus. Br J Pharmacol 149: 532-541.

5. Ma L, Lei Y, Xue Q, Wang SW, Yang DY, et al. (2003) [Effects of shenqifuxin oral liquid on the plasma kaliuretic peptide, the myocardial contractility and relaxation of left ventricle and the left ventricular remodeling in experimental rats with heart failure]. Zhongguo Zhong Yao Za Zhi 28: 656-660.

6. Wang Q (1992) [Inotropic action of Astragalus membranaceus Bge. saponins and its possible mechanism]. Zhongguo Zhong Yao Za Zhi 17: 557-559, inside backcover.

7. Zuo C, Xie XS, Qiu HY, Deng Y, Zhu D, et al. (2009) Astragalus mongholicus ameliorates renal fibrosis by modulating HGF and TGFbeta in rats with unilateral ureteral obstruction. J Zhejiang Univ Sci B 10: 380-390.

8. Tian Z, Liu SB, Wang YC, Li XQ, Zheng LH, et al. (2013) Neuroprotective effects of formononetin against NMDA-induced apoptosis in cortical neurons. Phytother Res 27: 1770-1775.
9. Jalsrai A, Grecksch G, Becker A (2010) Evaluation of the effects of Astragalus mongholicus Bunge saponin extract on central nervous system functions. J Ethnopharmacol 131: 544-549.

10. Aldarmaa J, Liu Z, Long J, Mo X, Ma J, et al. (2010) Anti-convulsant effect and mechanism of Astragalus mongholicus extract in vitro and in vivo: protection against oxidative damage and mitochondrial dysfunction. Neurochem Res 35: 33-41.

11. Gardiner KJ (2014) Pharmacological approaches to improving cognitive function in Down syndrome: current status and considerations. Drug Des Devel Ther 9: 103-125.

12. De la Fuente M, Cruces J, Hernandez O, Ortega E (2011) Strategies to improve the functions and redox state of the immune system in aged subjects. Curr Pharm Des 17: 3966-3993.

13. Obukuro K, Nobunaga M, Takigawa M, Morioka H, Hisatsune A, et al. (2013) Nitric oxide mediates selective degeneration of hypothalamic orexin neurons through dysfunction of protein disulfide isomerase. J Neurosci 33: 12557-12568.

14. Lei Y, Fu W, Chen J, Xiong C, Wu G, et al. (2011) J Ethnopharmacol 134: 275-280

15. Li Z, Zhang Z, Zhang J, Jia J, Ding J, et al. (2012) Cordyceps militaris extract attenuates D-galactose-induced memory impairment in mice. J Med Food 15: 1057-1063.

16. Lu J, Wu DM, Hu B, Zheng YL, Zhang ZF, et al. (2010) NGF-Dependent activation of TrkA pathway: A mechanism for the neuroprotective effect of troxerutin in D-galactose-treated mice. Brain Pathol 20: 952-965.

17. Xiao F, Li XG, Zhang XY, Hou JD, Lin LF, et al. (2011) Combined administration of D-galactose and aluminium induces Alzheimer-like lesions in brain. Neurosci Bull 27: 143-155.

18. Roher AE, Maarouf CL, Malek-Ahmadi M, Wilson J, Kokjohn TA, et al. (2013) Subjects harboring presenilin familial Alzheimer's disease mutations exhibit diverse white matter biochemistry alterations. Am J Neurodegener Dis 2: 187-207. 